\title{
Antimicrobial properties of a novel copper- based composite coating with potential for use in healthcare facilities
}

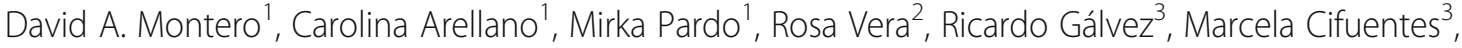
María A. Berasain ${ }^{3}$, Marisol Gómez ${ }^{4^{*}}$, Claudio Ramírez ${ }^{4^{*}}$ and Roberto M. Vidal ${ }^{1,5^{*}}$ (D)

\begin{abstract}
Background: Healthcare-associated infections (HAls) have a major impact on public health worldwide. Particularly, hospital surfaces contaminated with bacterial pathogens are often the origin of both sporadic cases and outbreaks of HAls. It has been demonstrated that copper surfaces reduce the microbial burden of high touch surfaces in the hospital environment. Here we report the antimicrobial characterization of a novel composite coating with embedded copper particles, named Copper Armour ${ }^{\mathrm{TM}}$.

Methods: The Copper Armour ${ }^{\mathrm{TM}}$ bactericidal activity was evaluated in in vitro assays against several bacterial pathogens, including Staphylococcus aureus, Pseudomonas aeruginosa, Escherichia coli O157:H7 and Listeria monocytogenes. Additionally, its antimicrobial properties were also evaluated in a pilot study over a nine-week period at an adult intensive care unit. For this, four high touch surfaces, including bed rails, overbed table, bedside table and IV Pole, were coated with Cooper Armour ${ }^{\mathrm{TM}}$, and its microbial burden was determined over a nine-week period.

Results: Copper Armour ${ }^{\mathrm{TM}}$ coated samples showed an in vitro reduction in bacterial burden of $>99.9 \%$ compared to control samples. Moreover, pilot study results indicate that Copper Armour ${ }^{\mathrm{TM}}$ significantly reduces the level of microbial contamination on high-touch surfaces in the hospital environment, as compared with standard surfaces.

Conclusions: Based on its antimicrobial properties, Copper Armour ${ }^{\mathrm{TM}}$ is a novel self-sanitizing coating that exhibits bactericidal activity against important human pathogens and significantly reduces the microbial burden of hospital surfaces. This composite could be used as a self-sanitizing coating to complement infection control strategies in healthcare facilities.
\end{abstract}

Keywords: Antimicrobial copper, Copper-based composite, Self-sanitizing coating, High-touch surfaces, Healthcareassociated infections

\section{Background}

Healthcare-associated infections (HAIs) are the most frequent adverse event threatening the life of hospitalized patients worldwide [1]. HAIs have a major impact on public health, as they increase the average length of hospital stays, morbidity and mortality $[2,3]$, and cause a significant increase in healthcare costs $[4,5]$.

\footnotetext{
* Correspondence: marisol@atacamalab.cl; claudio@atacamalab.cl; rvidal@uchile.cl

${ }^{4}$ ATACAMALAB, Lampa, Chile

${ }^{1}$ Programa de Microbiología y Micología, Instituto de Ciencias Biomédicas,

Facultad de Medicina, Universidad de Chile, Santiago, Chile

Full list of author information is available at the end of the article
}

Multiple factors contribute to the incidence of HAIs, including intrinsic patient conditions (e.g. their individual pathologies) and risk factors associated with the hospital environment. Specifically, medical devices and hospital surfaces contaminated with pathogenic microorganisms are often the origin of both sporadic cases and outbreaks of HAIs [2, 6, 7]. Pathogens, such as methicillin-resistant Staphylococcus aureus (MRSA), vancomycin-resistant Enterococcus spp. (VRE) and Clostridium difficile, are able to colonize hospital surfaces, and both spores and the vegetative form can persist on these surfaces for months [7]. Therefore, hand hygiene

(c) The Author(s). 2019 Open Access This article is distributed under the terms of the Creative Commons Attribution 4.0 International License (http://creativecommons.org/licenses/by/4.0/), which permits unrestricted use, distribution, and 
and routine and terminal cleaning of surfaces in contact with the patients are useful strategies to limit intra-hospital propagation of infectious agents $[8,9]$. At present, the microbiological standard used to evaluate and monitor terminal cleaning of hospital surfaces is a count of 250-500 aerobic colony-forming units (cfu) per $100 \mathrm{~cm}^{2}[10,11]$. However, while deep cleaning may remove the majority of microorganisms present on hospital surfaces, they are susceptible to recontamination, which in some cases occurs in a very short period of time [12].

In 2008, the United States Environmental Protection Agency (US EPA) recognized copper as the first antimicrobial metal. In in vitro assays, solid copper surfaces killed $99.9 \%$ of microorganisms within two hours of contact [13]. The rate of this antimicrobial activity has a magnitude of 7 to 8 logarithms per hour and generally no microorganisms are recovered after longer incubation periods [14]. Likewise, copper particles exhibit potent antimicrobial activity [15]. The bactericidal activity of copper is mainly attributed to the release of ions, which affect the integrity of the membrane and/or the bacterial wall, generate intracellular oxidative stress and are genotoxic, resulting in the death of microorganisms [14, 15]. One advantage of copper as a bactericidal agent is the low level of resistance among clinically relevant microorganisms. Copper-resistant mechanisms are primarily found in environmental microorganisms living in copper-rich niches, such as marine sediments and mines $[15,16]$.

Consequently, the number of studies evaluating the use of copper as a strategy for reducing the microbial burden in hospital environments and to prevent HAIs has increased in the past few years [11, 12, 17-23]. Results from these studies indicate that hospital surfaces coated with solid copper show sustained reduction in microbial burden compared to control surfaces. Nevertheless, additional studies are necessary to determine the impact of using copper-coated surfaces on the incidence of HAIs. While some studies concluded that using copper-coated surfaces reduces the rate of these infections [11,22], in others this reduction was not statistically significant [21]. Furthermore, heterogeneity in study design and data analysis among existing studies makes it hard to compare their results, and therefore to draw definitive conclusions $[24,25]$. Based on these observations, the use of copper-coated surfaces and medical devices is a promising strategy for controlling HAIs.

This report summarizes the development and antimicrobial characterization of a composite material that includes copper particles, named Copper Armour ${ }^{\text {Tw. }}$. Due to its initial liquid state, this novel composite can be used to impregnate various surfaces; after it dries $(\sim 2.5$ h) it provides a solid coating of $0.5-3.0 \mathrm{~mm}$ thick.
Many types of microorganisms can persist for extended periods of time on high-touch surfaces; therefore, this type of surfaces represent high risk spots for pathogen transmission and HAIs. In this context, a main concern is to eliminate as many pathogenic microorganisms as possible from these surfaces and limiting their transfer to patients [26] . Due to their antimicrobial properties, metals, including copper, have been a focus of interest as coating materials for surfaces. In this scenario, the aim of this study was to determine in situ whether a composite based on copper significantly reduced the microbial load on coated surfaces in an adult intensive care unit (ICU) when compared to control (i.e. non-coated) surfaces and, in parallel, to determine if a composite based on copper has in vitro antimicrobial activity against relevant pathogenic bacteria.

\section{Methods}

\section{Bacterial strains and culture conditions}

The microorganisms used in this study were obtained from American Type Culture Collection (ATCC) and they include: Staphylococcus aureus (ATCC 29213), Pseudomonas aeruginosa (ATCC 27853), Escherichia coli O157:H7 (ATCC 43895) and Listeria monocytogenes (ATCC 13932). S. aureus, P. aeruginosa and E. coli were routinely cultured in Trypticase Soy Broth (TSB, BD Difco $^{\mathrm{Tm}}$, USA) and Trypticase Soy Agar (TSA, BD Difco ${ }^{\mathrm{Tm}}$, USA) for $24-36 \mathrm{~h}$ at $37 \pm 0.5^{\circ} \mathrm{C}$. L. monocytogenes was routinely cultured in Brain Heart Infusion Broth (BHI, BD Difco ${ }^{\mathrm{T \omega}}$, USA) and BHI Agar (BD Difco ${ }^{\mathrm{Tm}}$, USA) for $24-48$ h at $37 \pm 0.5^{\circ} \mathrm{C}$.

\section{Formulation of copper Armour ${ }^{\mathrm{Tm}}$}

Copper Armour ${ }^{\mathrm{Tm}}$ is a composite material that is embedded with copper particles in a methyl methacrylate resin (matrix) evenly distributed in the matrix, so that copper particles are always partially exposed on the surface. To achieve this effect, at least four types of copper particles are used; as these particles differ in shape, apparent densities (with a range of $<1-8 \mathrm{~g} / \mathrm{cm}^{3}$; Fig. 1a, b) and capacity to be compacted among themselves, when mixed together in a polymeric matrix they can be distributed homogeneously in the entire thickness of the composite structure.

Three components were separately formulated. The first component, a polymeric base, includes an agglomerative or polymeric matrix with a dispersion of copper nanoparticles and microparticles $<20 \mu \mathrm{m}$; this dispersion is achieved by conventional methods using a high-shear mixing blade (Cowles), where nanoparticles $<0.1 \mu \mathrm{m}$ were previously homogenized by an ultrasonic agitator. This semi-manufactured product is filtered using a 200 -mesh $(74 \mu \mathrm{m})$ sieve prior to packaging. The second component, the active component, is made from larger 

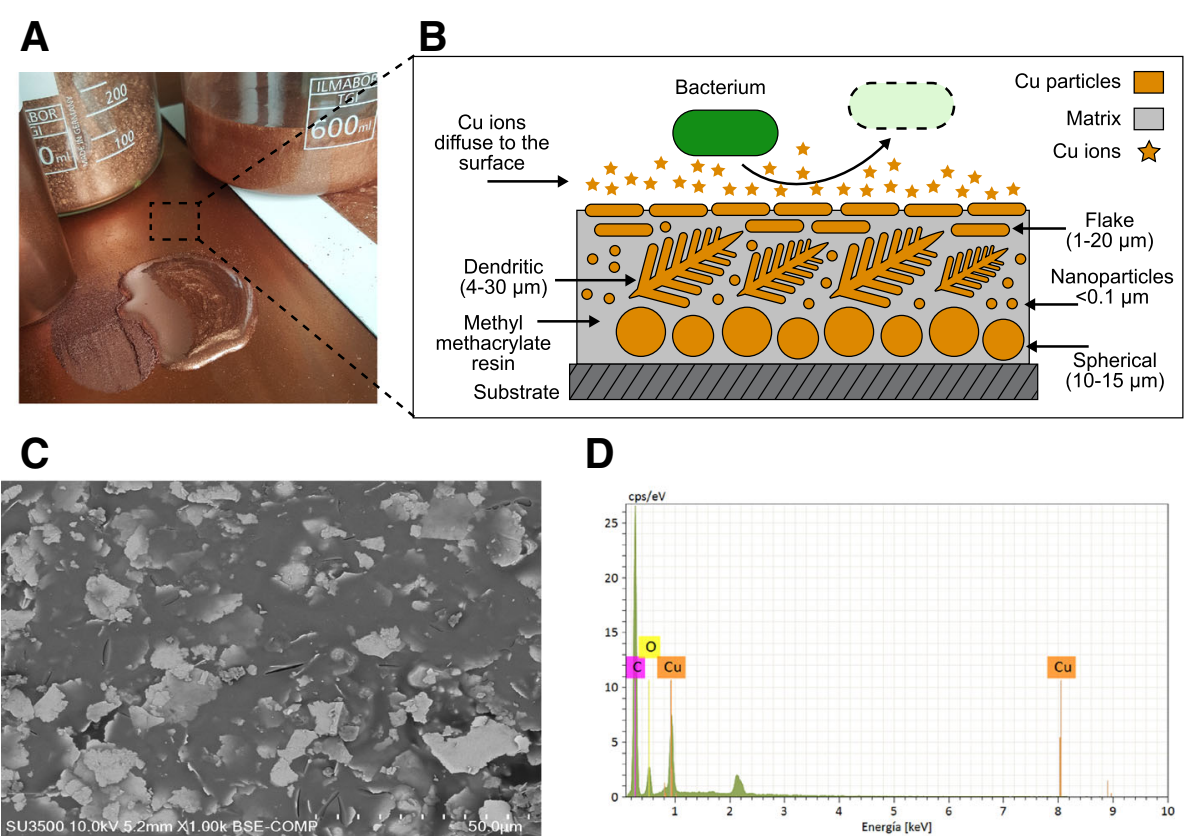

D

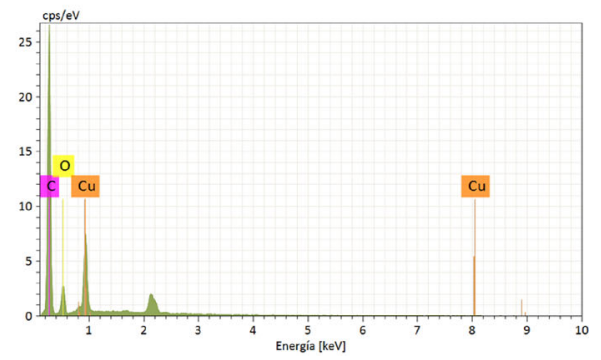

Fig. 1 Formulation of Copper Armour ${ }^{\mathrm{TM}}$. a Copper Armour ${ }^{\mathrm{TM}} \mathrm{can}$ be applied in liquid state on various substrates. At $25^{\circ} \mathrm{C}$, a $1 \mathrm{~mm}$ thick coating requires $2.5 \mathrm{~h}$ to dry. $\mathbf{b}$ Schematic composition of Copper Armour ${ }^{\mathrm{Tm}}$. Shapes and sizes of Cu particles embedded in the methacrylate resin (matrix) are shown; the matrix acts as a liquid medium, providing adherence to the substrate and cohesion among components. Larger spherical $\mathrm{Cu}$ particles precipitate before curing of the matrix. Dendritic Cu particles act as a charge-conducting network. Smaller flakes Cu particles, float on the surface and become oriented in parallel, increasing the contact surface, thus, favoring the release of Cu ions. A bacterium is shown with its membrane degraded as a consequence of the antimicrobial activity of Cu. c Superficial topography of Copper Armour ${ }^{\mathrm{TM}}$. SEM analysis showed a homogenous distribution of copper particles in the matrix. $\mathbf{d}$ Chemical composition of Copper Armour ${ }^{\mathrm{Tm}}$. EDAX analysis shows that $\mathrm{Cu}$, carbon (C) and oxygen $(\mathrm{O})$ are the main elements of the composite

copper particles, up to $60 \mu \mathrm{m}$, that are dry packaged after sieving and drying to avoid agglomeration. The third component, a hardener, is separately packaged in a third container, depending on the selected agglomerate.

The application of Copper Armour ${ }^{\mathrm{Tu}}$ is performed using a disperser, preferably electric from 200 to 600 $\mathrm{rpm}$, homogenizing the polymeric base with the active component. Then, the hardener is added and homogenized for at least one minute. This mixture must be applied within $10 \mathrm{~min}$ following preparation, as after 15 min it will begin to solidify.

For the assays described in this work, the Copper Armour $^{\text {ma }}$ formulation correspond to a $60 / 40$ copper/agglomerate total weight ratio. The agglomerative methyl methacrylate resin used was DEGADUR 527 (Evonik A.G., Germany), with powdered solid peroxide hardener. Copper Armour ${ }^{\mathrm{mi}}$ formulations are protected by Patent Cooperation Treaty international application number: PCT/CL2015/050058.

\section{Electron microscopy}

The superficial topography of Copper Armour ${ }^{\text {re }}$ was analyzed by scanning electron microscopy (SEM) using a Hitachi SU 3500 microscope coupled to a series 410-M detector, which allowed us to qualitatively analyze the elements present by Energy Dispersive X-ray spectroscopy (EDAX). Samples were coated with gold $(\mathrm{Au})$ to render them conductive.

\section{In vitro evaluation of antimicrobial activity}

The in vitro evaluation of antimicrobial activity was conducted based on two EPA protocols [27, 28], with slight modifications. The EPA designed these protocols to determine the efficacy of copper as a disinfectant, and to quantify the continuous reduction of bacterial contamination of non-porous surfaces containing copper and its alloys.

Test method of sanitizer activity (protocol 1) Two batches of test samples (each one consisting of five $2 \times 2$ $\mathrm{cm}$ aluminum sheets coated with Copper Armour ${ }^{\mathrm{nm}}$ ) and ten control samples $(2 \times 2 \mathrm{~cm}$ aluminum sheets $)$ were evaluated per microorganism. Test and control samples were cleaned using $70 \%$ ethanol and washed using sterile distilled water. Each sample was placed in a Petri dish and allowed to dry in a biological safety cabinet (Class II type A2, NuAire, USA), followed by exposure to ultraviolet light for $15 \mathrm{~min}$ per side.

Bacterial culture media were supplemented with 5\% heat-inactivated fetal calf serum (GIBCO, USA) and 
$0.01 \%$ Triton X-100 as organic sediment load. Initial inocula $\left(10^{7}\right.$ to $\left.10^{8} \mathrm{cfu}\right)$ were determined by serial dilutions in $1 \mathrm{X}$ phosphate-buffered saline (PBS) and plated in duplicate on TSA for $24-48 \mathrm{~h}$ at $37 \pm 0.5^{\circ} \mathrm{C}$. Test samples and controls were inoculated with $0.02 \mathrm{ml}$ of bacterial culture spread over $\sim 0.3 \mathrm{~cm}^{2}$ and allowed to dry for 20$40 \mathrm{~min}$. After $60 \mathrm{~min}$ of exposure (at room temperature) to the challenging microorganisms, samples were transferred to $20 \mathrm{ml}$ of neutralizing solution [TPL; Trypticase Soy Broth plus Polysorbate $80(1.5 \% \mathrm{v} / \mathrm{v})$ and Lecithin $(0.07 \% \mathrm{v} / \mathrm{v})]$, sonicated in an ultrasonic bath (Neytech ultrasonic cleaner, Model $19 \mathrm{H}$, USA) for $5 \mathrm{~min}$ and turned to mix. Within $1 \mathrm{~h}$, serial dilutions were performed in PBS and plated in duplicate on TSA. After incubation for $24-48 \mathrm{~h}$ at $37 \pm 0.5^{\circ} \mathrm{C}$, the number of cfu was counted. The number of cfu recovered per sample was determined taking into consideration the dilution (20x), using the following equation: $\mathrm{cfu} / \mathrm{sample}=(\mathrm{A} \times \mathrm{D}$ $x V) / V_{2}$, where $A=$ average cfu per sample, counted in duplicate; $\mathrm{D}=$ dilution factor; $\mathrm{V}=$ volume of TPL solution added; and $V_{2}=$ volume plated. The percentage reduction in the number of cfu for test samples as compared with the control samples was determined using the following equation: \% reduction $=[(a-b) / a] \times$ 100 where, $\mathrm{a}=$ geometric median of the number of $\mathrm{cfu}$ recovered in control samples; and $\mathrm{b}=$ geometric median of the number of cfu recovered in the test samples.

In addition, the following sterility control was performed: $0.1 \mathrm{ml}$ aliquots of culture media, PBS and TPL solution were plated on TSA and the absence of bacterial growth was confirmed. One test and one control sample, sterilized as previously described, were washed using $1 \mathrm{ml}$ of TPL solution, $0.1 \mathrm{ml}$ of this solution was plated on TSA and the absence of bacterial growth was confirmed. Finally, each microorganism was inoculated in $1 \mathrm{ml}$ of TPL solution, and it was determined that this solution did not inhibit bacterial growth.

Test method of continuous reduction of bacterial contamination (protocol 2) Two batches of test samples (each one consisting of three $2 \times 2 \mathrm{~cm}$ aluminum sheets coated with Copper Armour $\left.r^{\mathrm{Tw}}\right)$ and six control samples $(2 \times 2 \mathrm{~cm}$ aluminum sheets $)$ were evaluated per microorganism in a similar fashion to that described in Protocol 1. Samples were consecutively inoculated eight times, adding the challenging microorganism at $0,3,6$, $9,12,15,18$ and $21 \mathrm{~h}$. The antimicrobial efficacy was evaluated at $2,6,12,18$ and $24 \mathrm{~h}$, corresponding to 1,2 , 4, 6 and 8 inoculations. After exposure to bacteria, $20 \mathrm{ml}$ of TPL solution was added and samples were subjected to sonication in an ultrasonic bath and turned to mix. The determination of the number of cfu recovered per sample and the percent reduction was performed as described for protocol 1. Additionally, we performed the same sterility controls as previously described.

\section{Pilot study at an adult intensive care unit}

The study was conducted in two patient rooms (side by side) within the adult ICU at the Hospital Clínico Universidad de Chile located in Santiago, Chile. One of the rooms was defined as the control and in the other room, considered the intervention room, surfaces were coated with Copper Armour ${ }^{\mathrm{TM}}$ (Fig. 2a). The following
B

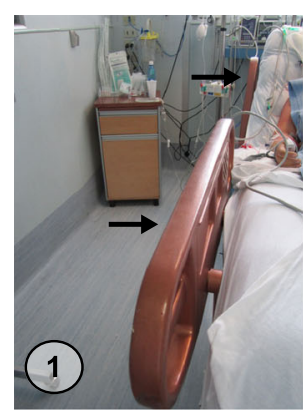

A


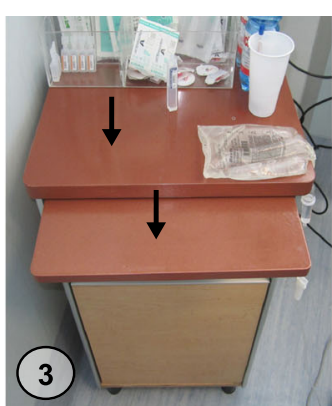

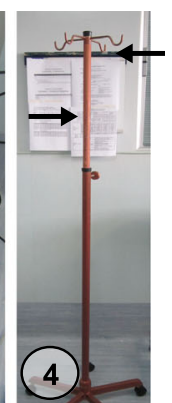

Fig. 2 Distribution of coated and sampled surfaces within the adult intensive care unit rooms. a Distribution of the sampled objects within the room. In the intervention room, the coated surfaces are shown in gold. b Copper Armour ${ }^{\mathrm{TM}}$ coated objects. (1) Bed rails, (2) Overbed table, (3) Bedside table and (4) IV Pole. Black arrows indicate where surface sampled were taken for each object 
surfaces were coated with Copper Armour ${ }^{\mathrm{rm}}$ : bed rails, overbed table, bedside table and IV Pole (Fig. 2b). Upon admission, patients were randomly assigned to either the control or intervention (Copper Armour ${ }^{\mathrm{rn}}$ ) room. Hand hygiene and cleaning protocols remained unaltered during the study.

The sampling protocol was performed over a nine-week period, during which the first week (basal week) was dedicated to methodology adjustments. Data obtained during this week were not included in statistical analysis and are not shown. Rooms were sampled on the same day and at the same time (before morning cleaning) every week throughout the study. Surfaces were sampled in duplicate (Fig. 2b, black arrows) using sterile plastic templates of $2 \times 12.5 \mathrm{~cm}$, in the case of bed rails the IV Pole, or $5 \times 5 \mathrm{~cm}$, in the case of the overbed and bedside tables. PBS humidified sterile dressing was vigorously scrubbed 10 times horizontally and 10 times vertically, covering the whole sampling area $\left(25 \mathrm{~cm}^{2}\right)$. Each dressing was placed in a $50 \mathrm{ml}$ sterile polypropylene centrifuge tube. Within $2 \mathrm{~h}$, three $\mathrm{ml}$ of PBS/LT ( $0.5 \%$ Tween 80 and $0.07 \%$ lecithin) were added to each centrifuge tube, vortexed for $1 \mathrm{~min}$, and allowed to settle for $5 \mathrm{~min}$. Subsequently, $100 \mu \mathrm{l}$ aliquots were plated on $5 \%$ sheep blood agar to estimate the total aerobic microbial burden present on sampled surface; mannitol salt agar (BD Difco ${ }^{\mathrm{Tn}}$, USA) to estimate the number of cfu of Staphylococcus spp.; MacConkey agar (BD Difco ${ }^{\mathrm{Tm}}$, USA) to determine the number of cfu of Gram-negative bacilli; chromogenic agar (BBLTM-BD CHROMagar MRSA ${ }^{\mathrm{m}}$, Becton Dickinson, USA) to estimate the number of cfu of MRSA; bile esculin agar (Becton Dickinson, USA) supplemented with vancomycin $(6 \mu \mathrm{g} / \mathrm{ml})$ to determine the number of cfu of VRE and Sabouraud agar (Becton Dickinson, USA) supplemented with chloramphenicol (CAF) to estimate the cfu of yeast / fungi. Plates were incubated for $24-48 \mathrm{~h}$ at $37 \pm 0.5^{\circ} \mathrm{C}$ and the number of cfu were determined. The number of cfu recovered per sample was reported as $\mathrm{cfu} / 100 \mathrm{~cm}^{2}$.

\section{Statistical analysis}

Data on microbial burden obtained from hospital surfaces were analyzed for normality using the Shapiro-Wilk test. As the data did not follow a normal distribution, the non-parametric Mann-Whitney $U$ test (one-tailed) was used to determine if the microbial burden of Copper Armour $^{\text {rm }}$ coated surfaces was significantly lower compared to control surfaces. Additionally, differences in the frequency of microbial burden, reported as $>250 \mathrm{cfu} / 100 \mathrm{~cm}^{2}$ surface, between control and Copper Armour ${ }^{\mathrm{mm}}$ coated surfaces was analyzed using the Fisher's exact test or the Pearson $X^{2}$ test (if all expected frequencies were $\geq 5$ ). A $P$-value of $<0.05$ was considered statistically significant; statistical analysis was performed in GraphPad Prism version 6.00 (GraphPad Software, La Jolla California USA).

\section{Results}

Characterization of the microstructure and chemical composition of copper Armour ${ }^{\mathrm{TM}}$

SEM analysis of samples coated with Copper Armour ${ }^{\text {tix }}$ showed a homogenous distribution of copper particles in the methacrylate matrix (Fig. 1c). Additionally, qualitative chemical analysis indicated that the main component in the coating was copper $(\mathrm{Cu})$, while carbon $(\mathrm{C})$ and oxygen (O) were the main matrix components (Fig. 1d).

\section{In vitro evaluation of the antimicrobial properties of copper Armour $^{\mathrm{TM}}$}

Challenging microorganisms for the evaluation of in vitro bactericidal activity were Staphylococcus aureus, Pseudomonas aeruginosa, Escherichia coli O157:H7 and Listeria monocytogenes. All experiments conducted with Copper Armour ${ }^{\mathrm{Ti}}$ coated samples showed a reduction, after $1 \mathrm{~h}$ of contact, in bacterial burden of $>99.9 \%$ compared to control samples (Table 1). Additionally, we determined that after consecutive inoculations over $24 \mathrm{~h}$, Copper Armour ${ }^{\mathrm{Tn}}$ coated samples continued to reduce the microbial burden by $>99.9 \%$ compared to control

Table 1 Reduction in bacterial burden after $1 \mathrm{~h}$ of contact with Copper Armour ${ }^{\mathrm{TM}}$ as compared to control surfaces

\begin{tabular}{|c|c|c|c|c|c|}
\hline \multirow[t]{2}{*}{ Microorganism } & \multirow[t]{2}{*}{ Batch } & \multirow{2}{*}{$\begin{array}{l}\text { Inoculum } \\
\text { (cfu) }\end{array}$} & \multicolumn{2}{|l|}{ Number of cfu recovered per sample ${ }^{*}$} & \multirow{2}{*}{$\begin{array}{l}\text { Reduction } \\
(\%)^{* *}\end{array}$} \\
\hline & & & Control & Copper ArmourTm & \\
\hline \multirow[t]{2}{*}{ S. aureus } & 1 & $4.3 \times 10^{7}$ & $1.2 \times 10^{6} ; 3.0 \times 10^{6} ; 1.8 \times 10^{6} ; 1.9 \times 10^{6} ; 3.1 \times 10^{6}$ & $<1 ;<1 ;<1 ;<1 ;<1$ & $>99.9$ \\
\hline & 2 & $1.5 \times 10^{7}$ & $1.4 \times 10^{6} ; 1.1 \times 10^{6} ; 1.1 \times 10^{6} ; 2.0 \times 10^{6} ; 1.2 \times 10^{6}$ & $<1 ;<1 ;<1 ;<1 ;<1$ & $>99.9$ \\
\hline \multirow[t]{2}{*}{ P. aeruginosa } & 1 & $1.6 \times 10^{8}$ & $4.4 \times 10^{7} ; 2.1 \times 10^{7} ; 7.2 \times 10^{6} ; 4.4 \times 10^{7} ; 9.3 \times 10^{6}$ & $<1 ;<1 ;<1 ;<1 ;<1$ & $>99.9$ \\
\hline & 2 & $1.8 \times 10^{8}$ & $1.1 \times 10^{7} ; 2.8 \times 10^{7} ; 1.2 \times 10^{7} ; 1.0 \times 10^{7} ; 1.1 \times 10^{7}$ & $<1 ;<1 ;<1 ;<1 ;<1$ & $>99.9$ \\
\hline \multirow[t]{2}{*}{ E. coli O157:H7 } & 1 & $1.9 \times 10^{7}$ & $8.1 \times 10^{5} ; 4.3 \times 10^{6} ; 4.1 \times 10^{6} ; 5.4 \times 10^{6} ; 9.6 \times 10^{5}$ & $<1 ;<1 ;<1 ;<1 ;<1$ & $>99.9$ \\
\hline & 2 & $2.4 \times 10^{7}$ & $5.3 \times 10^{6} ; 3.8 \times 10^{6} ; 2.4 \times 10^{6} ; 2.5 \times 10^{6} ; 7.9 \times 10^{5}$ & $<1 ;<1 ;<1 ;<1 ;<1$ & $>99.9$ \\
\hline \multirow[t]{2}{*}{ L. monocytogenes } & 1 & $3.2 \times 10^{7}$ & $7.2 \times 10^{6} ; 8.7 \times 10^{6} ; 9.4 \times 10^{6} ; 7.3 \times 10^{6} ; 6.3 \times 10^{6}$ & $<1 ;<1 ;<1 ;<1 ;<1$ & $>99.9$ \\
\hline & 2 & $1.6 \times 10^{7}$ & $9.7 \times 10^{6} ; 8.0 \times 10^{6} ; 7.3 \times 10^{6} ; 7.7 \times 10^{6} ; 7.8 \times 10^{6}$ & $<1 ;<1 ;<1 ;<1 ;<1$ & $>99.9$ \\
\hline
\end{tabular}

* Each value corresponds to the average of duplicates of cfu recovered in each one of the five samples evaluated per production batch. ${ }^{*}$ As compared with control samples 
samples (Table 2). Thus, Copper Armour ${ }^{\mathrm{Tw}}$ continuously reduced contamination caused by the bacteria evaluated here.

\section{Evaluation of the antimicrobial properties of copper Armour $^{\mathrm{TM}}$ at an adult intensive care unit}

Copper Armour ${ }^{\mathrm{Tm}}$ coated surfaces (Fig. 2) showed a reduction of the aerobic microbial burden compared to control surfaces; this reduction was statistically significant for bed rails $(66 \% ; p=0.018)$ and the overbed Table
(56\%; $p=0.045)$. Additionally, the average number of $\mathrm{cfu} / 100 \mathrm{~cm}^{2}$ for Staphylococcus spp. was lower on Copper Armour ${ }^{\text {Th }}$ coated surfaces compared to control surfaces (Table3); however, this reduction was only statistically significant in the case of bed rails $(88.9 \% ; p$ $<0.001)$. It is important to mention that during the study $S$. aureus was not recovered from any surface, and only one Copper Armour ${ }^{\text {ma }}$ coated surface was positive for Gram negative bacilli $\left(720 \mathrm{cfu} / 100 \mathrm{~cm}^{2}\right)$ and 2 for VRE (both samples with $120 \mathrm{cfu} / 100 \mathrm{~cm}^{2}$ ); due to these

Table 2 Continuous reduction of bacterial burden over $24 \mathrm{~h}$ of contact with Copper Armour ${ }^{\mathrm{TM}}$ as compared to control surfaces

\begin{tabular}{|c|c|c|c|c|c|}
\hline \multirow[t]{2}{*}{ Microorganism } & \multirow{2}{*}{$\begin{array}{l}\text { Time } \\
\text { (h) }\end{array}$} & \multirow[t]{2}{*}{ Batch } & \multicolumn{2}{|c|}{ Number of cfu recovered per sample * } & \multirow{2}{*}{$\begin{array}{l}\text { Reduction } \\
(\%)^{* *}\end{array}$} \\
\hline & & & Controls & Copper ArmourTm & \\
\hline \multirow[t]{5}{*}{ S. aureus Inoculum: $2.0 \times 10^{7}-5.0 \times 10^{7}$} & 2 & $\begin{array}{l}1 \\
2\end{array}$ & $\begin{array}{l}3.8 \times 10^{5} ; 3.1 \times 10^{5} ; 3.9 \times 10^{5} \\
4.0 \times 10^{5} ; 4.1 \times 10^{5} ; 3.2 \times 10^{5}\end{array}$ & $\begin{array}{l}<1 ;<1 ;<1 \\
<1 ;<1 ;<1\end{array}$ & $>99.9$ \\
\hline & 6 & $\begin{array}{l}1 \\
2\end{array}$ & $\begin{array}{l}1.8 \times 10^{6} ; 1.8 \times 10^{6} ; 2.0 \times 10^{6} \\
1.1 \times 10^{6} ; 1.5 \times 10^{6} ; 1.2 \times 10^{6}\end{array}$ & $\begin{array}{l}<1 ;<1 ;<1 \\
<1 ;<1 ;<1\end{array}$ & $>99.9$ \\
\hline & 12 & $\begin{array}{l}1 \\
2\end{array}$ & $\begin{array}{l}4.4 \times 10^{6} ; 4.5 \times 10^{6} ; 4.5 \times 10^{6} \\
3.9 \times 10^{6} ; 4.4 \times 10^{6} ; 4.0 \times 10^{6}\end{array}$ & $\begin{array}{l}<1 ;<1 ;<1 \\
<1 ;<1 ;<1\end{array}$ & $>99.9$ \\
\hline & 18 & $\begin{array}{l}1 \\
2\end{array}$ & $\begin{array}{l}6.6 \times 10^{6} ; 5.9 \times 10^{6} ; 6.1 \times 10^{6} \\
7.9 \times 10^{6} ; 6.4 \times 10^{6} ; 6.8 \times 10^{6}\end{array}$ & $\begin{array}{l}<1 ;<1 ;<1 \\
<1 ;<1 ;<1\end{array}$ & $>99.9$ \\
\hline & 24 & $\begin{array}{l}1 \\
2\end{array}$ & $\begin{array}{l}2.0 \times 10^{7} ; 1.0 \times 10^{7} ; 1.3 \times 10^{7} \\
1.0 \times 10^{7} ; 9.4 \times 10^{6} ; 9.9 \times 10^{6}\end{array}$ & $\begin{array}{l}<1 ;<1 ;<1 \\
<1 ;<1 ;<1\end{array}$ & $>99.9$ \\
\hline \multirow[t]{5}{*}{ P. aeruginosa Inoculum: $1.6 \times 10^{8}-1.8 \times 10^{8}$} & 2 & $\begin{array}{l}1 \\
2\end{array}$ & $\begin{array}{l}7.4 \times 10^{6} ; 7.4 \times 10^{6} ; 7.2 \times 10^{6} \\
6.2 \times 10^{6} ; 6.8 \times 10^{6} ; 6.5 \times 10^{6}\end{array}$ & $\begin{array}{l}<1 ;<1 ;<1 \\
<1 ;<1 ;<1\end{array}$ & $>99.9$ \\
\hline & 6 & $\begin{array}{l}1 \\
2\end{array}$ & $\begin{array}{l}7.6 \times 10^{6} ; 7.8 \times 10^{6} ; 7.6 \times 10^{6} \\
8.2 \times 10^{6} ; 7.8 \times 10^{6} ; 7.9 \times 10^{6}\end{array}$ & $\begin{array}{l}5800 ;<1 ; 2000 \\
<1 ;<1 ;<1\end{array}$ & $>99.9$ \\
\hline & 12 & $\begin{array}{l}1 \\
2\end{array}$ & $\begin{array}{l}1.6 \times 10^{7} ; 1.4 \times 10^{7} ; 1.3 \times 10^{7} \\
1.0 \times 10^{7} ; 1.1 \times 10^{7} ; 2.0 \times 10^{7}\end{array}$ & $\begin{array}{l}<1 ;<1 ;<1 \\
<1 ;<1 ;<1\end{array}$ & $>99.9$ \\
\hline & 18 & $\begin{array}{l}1 \\
2\end{array}$ & $\begin{array}{l}4.8 \times 10^{7} ; 4.8 \times 10^{7} ; 4.3 \times 10^{7} \\
5.0 \times 10^{7} ; 5.2 \times 10^{7} ; 4.9 \times 10^{7}\end{array}$ & $\begin{array}{l}<1 ;<1 ;<1 \\
<1 ;<1 ;<1\end{array}$ & $>99.9$ \\
\hline & 24 & $\begin{array}{l}1 \\
2\end{array}$ & $\begin{array}{l}1.1 \times 10^{8} ; 1.0 \times 10^{8} ; 9.6 \times 10^{7} \\
1.3 \times 10^{8} ; 2.0 \times 10^{8} ; 1.9 \times 10^{8}\end{array}$ & $\begin{array}{l}<1 ;<1 ;<1 \\
<1 ;<1 ;<1\end{array}$ & $>99.9$ \\
\hline \multirow[t]{5}{*}{ E. coli O157:H7 Inoculum: $2.0 \times 10^{7}-4.0 \times 10^{7}$} & 2 & $\begin{array}{l}1 \\
2\end{array}$ & $\begin{array}{l}2.8 \times 10^{5} ; 3.1 \times 10^{5} ; 3.0 \times 10^{5} \\
3.5 \times 10^{5} ; 3.5 \times 10^{5} ; 3.3 \times 10^{5}\end{array}$ & $\begin{array}{l}<1 ;<1 ;<1 \\
<1 ;<1 ;<1\end{array}$ & $>99.9$ \\
\hline & 6 & $\begin{array}{l}1 \\
2\end{array}$ & $\begin{array}{l}1.6 \times 10^{6} ; 1.7 \times 10^{6} ; 1.6 \times 10^{6} \\
2.2 \times 10^{6} ; 1.9 \times 10^{6} ; 2.0 \times 10^{6}\end{array}$ & $\begin{array}{l}<1 ;<1 ;<1 \\
<1 ;<1 ;<1\end{array}$ & $>99.9$ \\
\hline & 12 & $\begin{array}{l}1 \\
2\end{array}$ & $\begin{array}{l}4.6 \times 10^{6} ; 4.6 \times 10^{6} ; 4.5 \times 10^{6} \\
4.2 \times 10^{6} ; 4.9 \times 10^{6} ; 4.3 \times 10^{6}\end{array}$ & $\begin{array}{l}<1 ;<1 ;<1 \\
<1 ;<1 ;<1\end{array}$ & $>99.9$ \\
\hline & 18 & $\begin{array}{l}1 \\
2\end{array}$ & $\begin{array}{l}9.8 \times 10^{6} ; 1.1 \times 10^{7} ; 9.5 \times 10^{6} \\
1.2 \times 10^{7} ; 1.0 \times 10^{7} ; 1.0 \times 10^{7}\end{array}$ & $\begin{array}{l}<1 ;<1 ;<1 \\
<1 ;<1 ;<1\end{array}$ & $>99.9$ \\
\hline & 24 & $\begin{array}{l}1 \\
2\end{array}$ & $\begin{array}{l}3.2 \times 10^{7} ; 3.0 \times 10^{7} ; 2.9 \times 10^{7} \\
3.9 \times 10^{7} ; 4.1 \times 10^{7} ; 4.0 \times 10^{7}\end{array}$ & $\begin{array}{l}<1 ;<1 ;<1 \\
<1 ;<1 ;<1\end{array}$ & $>99.9$ \\
\hline \multirow[t]{5}{*}{ L. monocytogenes Inoculum: $1.0 \times 10^{7}-5.0 \times 10^{7}$} & 2 & $\begin{array}{l}1 \\
2\end{array}$ & $\begin{array}{l}1,6 \times 10^{7} ; 2,1 \times 10^{7} ; 2,2 \times 10^{7} \\
1,5 \times 10^{7} ; 1,4 \times 10^{7} ; 2,1 \times 10^{7}\end{array}$ & $\begin{array}{l}<1 ;<1 ;<1 \\
<1 ;<1 ;<1\end{array}$ & $>99.9$ \\
\hline & 6 & $\begin{array}{l}1 \\
2\end{array}$ & $\begin{array}{l}3,0 \times 10^{7} ; 4,1 \times 10^{7} ; 4,3 \times 10^{7} \\
3,6 \times 10^{7} ; 3,7 \times 10^{7} ; 2,7 \times 10^{7}\end{array}$ & $\begin{array}{l}<1 ;<1 ;<1 \\
<1 ;<1 ;<1\end{array}$ & $>99.9$ \\
\hline & 12 & $\begin{array}{l}1 \\
2\end{array}$ & $\begin{array}{l}4,8 \times 10^{7} ; 5,1 \times 10^{7} ; 6,0 \times 10^{7} \\
4,7 \times 10^{7} ; 4,7 \times 10^{7} ; 4,1 \times 10^{7}\end{array}$ & $\begin{array}{l}<1 ;<1 ;<1 \\
<1 ;<1 ;<1\end{array}$ & $>99.9$ \\
\hline & 18 & $\begin{array}{l}1 \\
2\end{array}$ & $\begin{array}{l}9,8 \times 10^{7} ; 9,1 \times 10^{7} ; 9,8 \times 10^{7} \\
9,2 \times 10^{7} ; 9,4 \times 10^{7} ; 9,0 \times 10^{7}\end{array}$ & $\begin{array}{l}<1 ;<1 ;<1 \\
<1 ;<1 ;<1\end{array}$ & $>99.9$ \\
\hline & 24 & $\begin{array}{l}1 \\
2\end{array}$ & $\begin{array}{l}2,2 \times 10^{8} ; 2,0 \times 10^{8} ; 2,1 \times 10^{8} \\
1,9 \times 10^{8} ; 1,2 \times 10^{8} ; 1,2 \times 10^{8}\end{array}$ & $\begin{array}{l}<1 ;<1 ;<1 \\
<1 ;<1 ;<1\end{array}$ & $>99.9$ \\
\hline
\end{tabular}

* Each value corresponds to the average of duplicates of cfu recovered in each one of the three samples evaluated per production batch. ${ }^{* *}$ As compared with control samples 
low detection rates, these microorganisms were not included in statistical analyses. In contrast, we did not observe a reduction in the average burden of yeasts / fungi on Copper Armour ${ }^{\mathrm{Tn}}$ coated surfaces as compared to control surfaces. Nevertheless, the isolation of these microorganisms was sporadic overall, with values $<250$ $\mathrm{cfu} / 100 \mathrm{~cm}^{2}$ during the study.

In agreement with previous results, the frequency of samples with a microbial burden $>250 \mathrm{cfu} / 100 \mathrm{~cm}^{2}$ was lower in the case of Copper Armour ${ }^{\mathrm{mu}}$ coated surfaces compared to control surfaces (Fig. 3); this difference was statistically significant for bed rails (40.6\% Copper Armour $^{\text {max }}$ versus $68.8 \%$ control; $p=0.023)$ and the overbed Table $(35.7 \%$ Copper Armour ${ }^{\mathrm{m}}$ versus 75\% control; $p=0.030$ ) (Table 4). Furthermore, the overall frequency of control surfaces with a microbial burden of $>250 \mathrm{cfu} / 100 \mathrm{~cm}^{2}$ was significantly greater than Copper Armour coated surfaces, 60\% (48/80) versus $33.3 \%(p=0.007)$. Thus, Copper Armour ${ }^{\mathrm{Tm}}$ exhibits antimicrobial properties able to decrease the microbial burden of high-touch surfaces in a hospital environment. Therefore, compared to control surfaces, Copper Armour ${ }^{\mathrm{Tm}}$ coated surfaces were more likely to meet the threshold required for successful terminal cleaning (i.e. $<250 \mathrm{cfu} / 100$ $\mathrm{cm}^{2}$ ), indicating that the use of this composite could contribute to schemes and practices aimed at controlling HAIs.

\section{Discussion}

It has been demonstrated that high-touch surfaces in the hospital environment are an important reservoir for infectious agents causing HAIs $[6,29]$. In this context, a considerable number of studies have provided experimental evidence indicating that hospital surfaces coated with copper have lower microbial burden levels compared to standard surfaces, which in some cases have been associated with a reduction in the incidence of HAIs [11, 12, 17-23]. However, while most of these studies have been conducted using solid copper and its alloys, the in vitro and in situ evaluation of polymeric matrices and composites containing copper particles has been limited [30-33].
Our results indicate that Copper Armour ${ }^{\text {Tix }}$ may be used as a self-sanitizing coating to modify existing hospital surfaces, avoiding the structural restrictions imposed by a change to solid copper. Due to its initial liquid state and subsequent hardening, this composite can be used to coat surfaces of various sizes, shapes and compositions, which reduces the cost and quantity of copper required.

The in vitro evaluation of the antimicrobial properties of Copper Armour ${ }^{\mathrm{m} w}$ showed that this composite material exhibits a potent bactericidal activity against $S$. aureus, P. aeruginosa, E. coli $\mathrm{O} 157: \mathrm{H} 7$ and L. monocytogenes. As reported for solid copper, Copper Armour ${ }^{\text {rn }}$ killed more than $99.9 \%$ of these microorganisms after one hour of contact, as well as after consecutive inoculations over $24 \mathrm{~h}$ (Table $1 \&$ Table 2). It is noteworthy that two of these microorganisms, $S$. aureus and $P$. aeruginosa, are among the principal pathogens causing HAIs worldwide [34-36]. Moreover, the emergence of resistant and multiresistant bacteria makes it necessary to develop new biocidal materials and agents able to limit the dissemination and, at the same time, contribute to the elimination of these pathogens.

We also evaluated the Copper Armour ${ }^{\mathrm{rm}}$ antimicrobial properties in a hospital environment. Our pilot study indicated that Copper Armour ${ }^{\mathrm{mm}}$ reduces the microbial burden of hospital surfaces, even under present day protocols of extreme hygiene. A study by Attaway et al. [6] showed that bed rails in ICUs are rapidly colonized after cleaning with two commercial disinfectants, exceeding the threshold of $250 \mathrm{cfu} / 100$ $\mathrm{cm}^{2}$ after $2.5 \mathrm{~h}$. In that study, the average microbial burden found on bed rails before cleaning was 4.756 $\mathrm{cfu} / 100 \mathrm{~cm}^{2}$ (median $1.665 \mathrm{cfu} / 100 \mathrm{~cm}^{2}$ ). Likewise, our results showed that control bed rails had an average microbial burden of $3.323 \mathrm{cfu} / 100 \mathrm{~cm}^{2}$ (median 1.440 $\mathrm{cfu} / 100 \mathrm{~cm}^{2}$ ) (Table 3). On the contrary, Copper Armour $^{\mathrm{Tm}}$ coated bed rails showed an average microbial burden of $1.129 \mathrm{cfu} / 100 \mathrm{~cm}^{2}$ (median $120 \mathrm{cfu} / 100$ $\mathrm{cm}^{2}$ ), which corresponds to a significant reduction

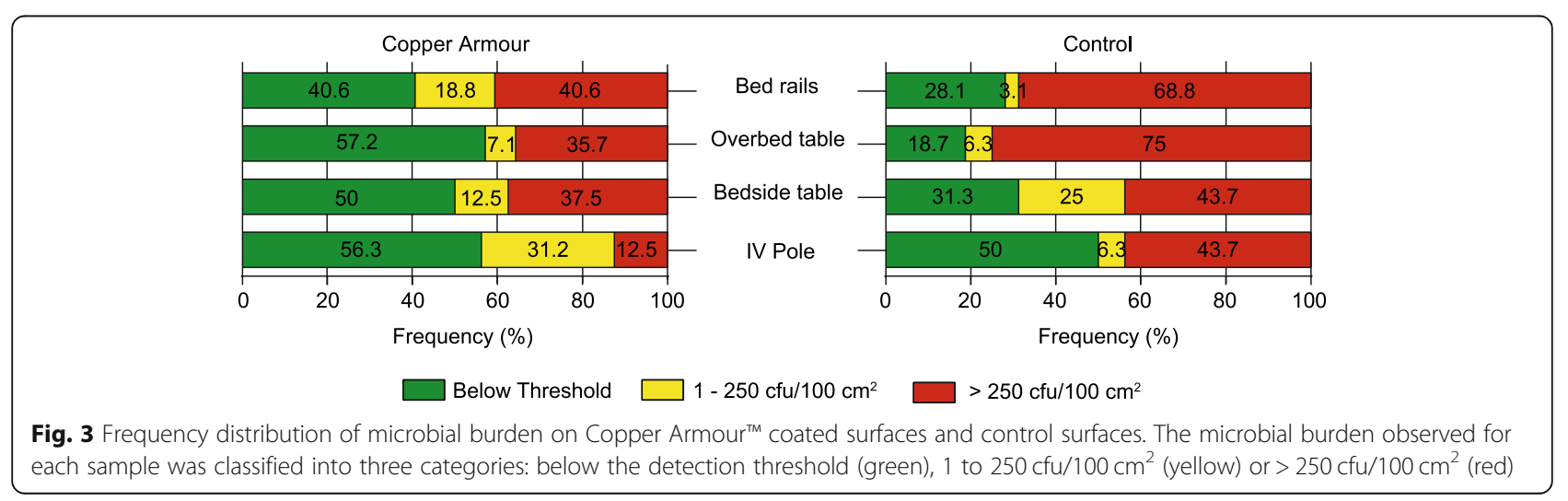


Table 3 Bacterial burden on Copper Armour ${ }^{\mathrm{TM}}$ coated surfaces and control surfaces during 8 weeks of pilot study in an adult intensive care unit

\begin{tabular}{|c|c|c|c|c|c|c|c|c|}
\hline \multirow[t]{2}{*}{ Evaluated object } & \multicolumn{3}{|c|}{ Copper Armour $^{\mathrm{TM}}$} & \multicolumn{3}{|c|}{ Control } & \multirow[t]{2}{*}{$P$ value } & \multirow[t]{2}{*}{$\%$ Reduction } \\
\hline & $\mathrm{n}$ & Average $\mathrm{cfu} / 100 \mathrm{~cm}^{2}$ & Media cfu/100 $\mathrm{cm}^{2}$ & $\mathrm{n}$ & Average cfu/100 $\mathrm{cm}^{2}$ & Median cfu/100 $\mathrm{cm}^{2}$ & & \\
\hline \multicolumn{9}{|c|}{ Total aerobic microbial load } \\
\hline Bed rails & 32 & 1129 & 120 & 32 & 3323 & 1440 & $0.018 *$ & 66.0 \\
\hline Overbed Table & 14 & 762,9 & 0 & 16 & 1755 & 960 & $0,045 *$ & 56.5 \\
\hline Bedside Table & 16 & 1793 & 60 & 16 & 2108 & 120 & 0,303 & 14.9 \\
\hline IV Pole & 16 & 157,5 & 0 & 16 & 337,5 & 120 & 0,195 & 53.5 \\
\hline \multicolumn{9}{|l|}{ Staphylococcus spp. } \\
\hline Bed rails & 32 & 270 & 0 & 32 & 2445 & 300 & $0,001 * *$ & 88.9 \\
\hline Overbed Table & 14 & 462,9 & 0 & 16 & 720 & 240 & 0,106 & 35.7 \\
\hline Bedside Table & 16 & 270 & 0 & 16 & 997,5 & 0 & 0,289 & 72.9 \\
\hline IV Pole & 16 & 22,5 & 0 & 16 & 60 & 0 & 0,231 & 62.5 \\
\hline \multicolumn{9}{|l|}{ Yeasts/Fungi } \\
\hline Bed rails & 32 & 697,5 & 0 & 32 & 195,0 & 0 & - & - \\
\hline Overbed Table & 14 & 68,5 & 0 & 16 & 15,00 & 0 & - & - \\
\hline Bedside Table & 16 & 630 & 0 & 16 & 1155 & 0 & 0,279 & 45.5 \\
\hline IV Pole & 16 & 15 & 0 & 16 & 37,5 & 0 & 0,367 & 60 \\
\hline
\end{tabular}

${ }^{*} \mathrm{p}<0.05,{ }^{*} \mathrm{p}<0.001$ established using Mann-Whitney $\mathrm{U}$ test (one-tailed)

(66\%; $p=0.018)$ compared to control bed rails. Thus, Copper Armour ${ }^{\mathrm{TM}}$ exhibits antimicrobial properties able to decrease the microbial burden of high-touch surfaces in a hospital environment. Therefore, compared to control surfaces, Copper Armour ${ }^{\mathrm{TM}}$ coated surfaces were more likely to meet the threshold required for successful terminal cleaning (i.e. $<250 \mathrm{cfu} /$ $100 \mathrm{~cm}^{2}$ ), indicating that the use of this composite could contribute to schemes and practices aimed at controlling HAIs.

It must be noted that two previous studies demonstrated that bed rails of solid copper showed a significantly lower average microbial burden compared to control bed rails [12, 37]. Also, in agreement with our results, in those studies it was determined that Staphylococcus spp. were the main bacterial group contaminating ICU bed rails. In fact, Copper Armour ${ }^{\mathrm{TM}}$ coated bed rails showed a significant $(88.9 \%, p<0.001)$ reduction in the average burden of Staphylococcus spp. compared to control bed rails (Table 3 ).

The overbed table is another Copper Armour ${ }^{\mathrm{Ts}}$ coated surface in which a significant reduction $(56 \%, p=0.045)$ of microbial burden was observed compared to the control overbed table. Besides, a lower average burden of Staphylococcus spp. was observed in the Copper Armour $^{\mathrm{Tm}}$ coated overbed table compared to the control overbed table, but in this case, the reduction, while showing a trend, was not significant $(p=0.105)$; this is likely due to the fact that the average burden of these microorganism on the control surface was also low. Previous studies have also shown that solid copper coated overbed tables have lower level of microbial burden compared to standard surfaces [37].

An intriguing result was the average microbial burden of the Copper Armour ${ }^{\mathrm{Tm}}$ coated bedside tables compared to the control. In this case, only a small and

Table 4 Frequency of a microbial burden of $>250 \mathrm{cfu} / 100 \mathrm{~cm}^{2}$ on Copper Armour ${ }^{\mathrm{TM}}$ coated surfaces and control surfaces

\begin{tabular}{|c|c|c|c|c|c|}
\hline \multirow{2}{*}{$\begin{array}{l}\text { Evaluated } \\
\text { objects }\end{array}$} & \multicolumn{2}{|c|}{ Copper Armour $^{\mathrm{TM}}$} & \multicolumn{2}{|c|}{ Control } & \multirow[t]{2}{*}{$P$ value } \\
\hline & $\mathrm{n}$ & Number (\%) of samples having $>250 \mathrm{cfu} / 100 \mathrm{~cm}^{2}$ & $\mathrm{n}$ & Number (\%) of samples having $>250 \mathrm{cfu} / 100 \mathrm{~cm}^{2}$ & \\
\hline Bed rails & 32 & $13(40.6)$ & 32 & $22(68.8)$ & $0.023 *$ \\
\hline Overbed Table & $14^{* *}$ & $5(35.7)$ & 16 & $12(75)$ & $0.030 *$ \\
\hline Bedside Table & 16 & $6(37.5)$ & 16 & $7(43.7)$ & 0.718 \\
\hline IV Pole & 16 & $2(12.5)$ & 16 & $7(43.7)$ & 0.113 \\
\hline Total & 78 & $26(33.3)$ & 80 & $48(60)$ & $0.001 * *$ \\
\hline
\end{tabular}

${ }^{*} p<0.05,{ }^{* *} p<0.001$ established using either Pearson $x^{2}$ or Fisher's Exact tests

**Two samples were discarded because the surface was contaminated with blood 
non-significant reduction $(p=0.289)$ of contamination levels was observed (Table 3 \& Table 4). A possible explanation for this result is that objects brought into the hospital, which escape cleaning schemes, are constantly placed on the bedside table (Fig. 2b).

It has been reported that among the objects located within a patient's room, the IV pole shows, in general, the lowest average microbial burden [18, 37]. This was also observed in the present study. It is likely that for this reason we were not able to observe differences between the average microbial burden of a Copper Armour $^{\mathrm{rm}}$ coated IV pole and the control surface. Nevertheless, $87.5 \%(14 / 16)$ of the samples from the Copper Armour ${ }^{\text {Tx }}$ coated IV Pole showed levels $<250 \mathrm{cfu} / 100 \mathrm{~cm}^{2}$ as compared to a $56.3 \%$ (9/ 16) of control samples (Fig. 3). This suggests that, in the case of surfaces exposed to low levels of contamination, the main benefit provided by Copper Armour $^{\mathrm{max}}$ would be to extended protection time of the terminal cleaning.

The pilot study also attempted to investigate the antifungal properties of Copper Armour ${ }^{\mathrm{Tm}}$. Nevertheless, we were not able to complete this aim as isolation of fungi/ yeast was sporadic and with low numbers of cfu/100 $\mathrm{cm}^{2}$. Therefore, in order to evaluate this property, it would be necessary to implement a different methodological design.

Finally, our pilot study did not include parameters, such as whether the room was occupied / unoccupied each day or epidemiological data of the patients. Future studies, that are longer in duration and that include different hospital surfaces beyond those tested here, and that also consider patient factors are necessary to further evaluate the possible impact of Copper Armour ${ }^{\text {Twm }}$ on the incidence of HAIs.

\section{Conclusions}

Our study suggests that Copper Amour TM, a novel self-sanitizing coating, exhibits bactericidal activity against important human pathogens and significantly reduces the microbial burden of hospital surfaces. Consequently, this novel composite could be used to complement infection control strategies in healthcare facilities.

\footnotetext{
Abbreviations

ATCC: American Type Culture Collection; Au: Gold; BD: Becton Dickinson; cfu: colony-forming units; EDAX: Energy Dispersive X-ray spectroscopy; GIBCO: Grand Island Biological Company; HAl: Healthcare-associated infection; ICU: Intensive Care Unit; MRSA: Methicillin-Resistant Staphylococcus aureus; PBS: Phosphate-Buffered Saline; PBS/LT: Phosphate-Buffered Saline/ Tween and Lecithin; PCT: Patent Cooperation Treaty; SEM: Scanning Electron Microscopy; TM: Trade Mark; TPL: Trypticase Soy Broth plus Polysorbate and Lecithin; TSA: Trypticase Soy Agar; TSB: Trypticase Soy Broth; US EPA: United States Environmental Protection Agency; VRE: Vancomycin-Resistant Enterococcus spp
}

\section{Acknowledgements}

Not applicable.

\section{Funding}

The authors gratefully acknowledge the financial support of Corporación de Fomento a la Producción (CORFO), Grant ID 17ITE2-82627.

\section{Availability of data and materials}

Data sharing not applicable to this article as no datasets were generated or analyzed during the current study.

\section{Authors' contribution}

MG, CR and RMV conceptualized and designed the study. CA and MP sampling and processing in the microbiological laboratory. RV performed the electron microscopy analyses. RG, MC and MB coordinated and design the study in situ at the Hospital Clínico Universidad de Chile. RMV and DAM data acquisition, data analysis, data interpretation, revised the manuscript, prepared figures and tables. All authors contributed to the editing and approved the final manuscript version.

\section{Ethics approval}

The Ethics Committee of the Hospital Clínico de la Universidad de Chile approved the study protocols and an informed consent was not required to obtain samples from hospital surfaces.

\section{Consent for publication}

Not applicable.

\section{Competing interests}

$M G$ and $C R$ are Directors of ATACAMALAB, a for profit Company aiming to develop energy efficient products including novel uses for copper.

\section{Publisher's Note}

Springer Nature remains neutral with regard to jurisdictional claims in published maps and institutional affiliations.

\section{Author details \\ ${ }^{1}$ Programa de Microbiología y Micología, Instituto de Ciencias Biomédicas, Facultad de Medicina, Universidad de Chile, Santiago, Chile. ${ }^{2}$ Instituto de Química, Facultad de Ciencias, Pontificia Universidad Católica de Valparaíso, Valparaíso, Chile. ${ }^{3}$ Unidad de Cuidados Intensivos, Facultad de Medicina, Hospital Clínico Universidad de Chile, Santiago, Chile. ${ }^{4}$ ATACAMALAB, Lampa, Chile. ${ }^{5}$ Instituto Milenio de Inmunología e Inmunoterapia, Facultad de Medicina, Universidad de Chile, Santiago, Chile.}

Received: 14 August 2018 Accepted: 17 December 2018 Published online: 05 January 2019

References

1. Allegranzi B, Nejad SB, Combescure C, Graafmans W, Attar H, Donaldson L, et al. Burden of endemic health-care-associated infection in developing countries: systematic review and meta-analysis. Lancet Elsevier Ltd. 2011; 377:228-41.

2. Ministerio de Salud. Gobierno de Chile. Informe de Vigilancia de Infecciones Asociadas a la Atención en Salud [Internet]. 2015. Available from: http:// web.minsal.cl/wp-content/uploads/2017/09/informe-vigilancia-2015.pdf

3. Barriga J, Cerda J, Abarca K, Ferrés M, Fajuri P, Riquelme M, et al. Infecciones asociadas a la atención en salud (IAAS) en pacientes pediátricos postoperados de cardiopatías congénitas. Rev Chil infectología Sociedad Chilena de Infectología. 2014;31:16-20.

4. Scott RD. The direct medical costs of healthcare-associated infections in U.S. hospitals and the benefits of prevention [internet]. Atlanta: centers for disease control and Prevention; 2009. Available from: http://www.cdc.gov/ hai/pdfs/hai/scott_costpaper.pdf

5. Pola B, Nercelles P, Pohlenza M, Otaiza F. Costo de las infecciones intrahospitalarias en hospitales chilenos de alta y mediana complejidad. Rev Chil infectología. Sociedad Chilena de Infectología. 2003;20:285-90.

6. Attaway HH, Fairey S, Steed LL, Salgado CD, Michels HT, Schmidt MG Intrinsic bacterial burden associated with intensive care unit hospital beds: effects of disinfection on population recovery and mitigation of potential infection risk. Am J Infect Control. Elsevier Inc. 2012;40:907-12. 
7. Kramer A, Schwebke I, Kampf G. How long do nosocomial pathogens persist on inanimate surfaces? A systematic review. BMC Infect Dis. 2006;6: $1-8$.

8. Pittet D, Donaldson L. Clean care is safer care: the first global challenge of the WHO world Alliance for patient safety. Am J Infect Control. 2005;33:476-9.

9. Rutala WA, Weber DJ. Guideline for disinfection and sterilization in healthcare facilities guideline for disinfection and sterilization in healthcare facilities, 2008 [internet]. Atlanta: centers for disease control and Prevention; 2008. Available from: https://www.cdc.gov/infectioncontrol/guidelines/ disinfection/

10. Lewis T, Griffith C, Gallo M, Weinbren M. A modified ATP benchmark for evaluating the cleaning of some hospital environmental surfaces. J Hosp Infect. 2008;69:156-63.

11. Salgado CD, Sepkowitz KA, John JF, Cantey JR, Attaway HH, Freeman KD, et al. Copper surfaces reduce the rate of healthcare-acquired infections in the intensive care unit. Infect Control Hosp Epidemiol. 2013;34:479-86.

12. Schmidt MG, Attaway HH, Fairey SE, Steed LL, Michels HT, Salgado CD. Copper continuously limits the concentration of bacteria resident on bed rails within the intensive care unit. Infect Control Hosp Epidemiol. 2013;34: 530-3.

13. Prado J V, Vidal A R, Durán T C. Aplicación de la capacidad bactericida del cobre en la práctica médica. Rev Med Chil. 2012;140:1325-32.

14. Grass G, Rensing C, Solioz M. Metallic copper as an antimicrobial surface. Appl Environ Microbiol. 2011;77:1541-7.

15. Vincent M, Duval RE, Hartemann P, Engels-Deutsch M. Contact killing and antimicrobial properties of copper. J Appl Microbiol. 2018:1-15.

16. Besaury L, Bodilis J, Delgas F, Andrade S, De la Iglesia R, Ouddane B, et al. Abundance and diversity of copper resistance genes cusA and copA in microbial communities in relation to the impact of copper on Chilean marine sediments. Mar Pollut Bull. 2013:67:16-25.

17. Hinsa-Leasure SM, Nartey Q, Vaverka J, Schmidt MG. Copper alloy surfaces sustain terminal cleaning levels in a rural hospital. Am J Infect Control. Elsevier Inc.; 2016;PubAh:e195-e203.

18. Schmidt MG, Von Dessauer B, Benavente C, Benadof D, Cifuentes P, Elgueta A, et al. Copper surfaces are associated with significantly lower concentrations of bacteria on selected surfaces within a pediatric intensive care unit. Am J Infect Control Elsevier Inc. 2016;44:203-9.

19. Karpanen TJ, Casey AL, Lambert PA, Cookson BD, Nightingale P, Miruszenko $L$, et al. The antimicrobial efficacy of copper alloy furnishing in the clinical environment: A crossover study. Infect Control Hosp Epidemiol. 2012;33:3-9.

20. Marais F, Mehtar S, Chalkley L. Antimicrobial efficacy of copper touch surfaces in reducing environmental bioburden in a south African community healthcare facility. J Hosp Infect The Hospital Infection Society. 2010;74:80-2.

21. Rivero $P$, Brenner $P$, Nercelles $P$. Impact of copper in the reduction of hospital-acquired infections, mortality and antimicrobial costs in the adult intensive care unit. Rev Chil Infectol. 2014:31:274-9.

22. Sifri CD, Burke GH, Enfield KB. Reduced health care-associated infections in an acute care community hospital using a combination of self-disinfecting copper-impregnated composite hard surfaces and linens. Am J Infect Control Elsevier Inc. 2016;44:1565-71.

23. von Dessauer B, Navarrete MS, Benadof D, Benavente C, Schmidt MG. Potential effectiveness of copper surfaces in reducing health care-associated infection rates in a pediatric intensive and intermediate care unit: $A$ nonrandomized controlled trial. Am J Infect Control. Elsevier Inc. 2016;44: e133-9.

24. Weber DJ, Otter JA, Rutala WA. Can copper-coated surfaces prevent healthcare-associated infections? Infect Control Hosp Epidemiol. 2017;38: 772-6.

25. Chyderiotis S, Legeay C, Verjat-Trannoy D, Le Gallou F, Astagneau P, Lepelletier D. New insights on antimicrobial efficacy of copper surfaces in the healthcare environment: a systematic review. Clin Microbiol Infect European Society of Clinical Microbiology and Infectious Diseases. 2018

26. Sandle T. Antimicrobial copper surfaces in hospitals. Clin Serv J. 2017;16:47-51.

27. United States Environmental Protection Agency. Test method for efficacy of copper alloy surfaces as a sanitizer. Washington: DC; 2014.

28. United States Environmental Protection Agency. Test method for the continuous reduction of bacterial contamination on copper alloy surfaces. Washington, DC; 2015.

29. Dancer SJ. The role of environmental cleaning in the control of hospitalacquired infection. J Hosp Infect Elsevier Ltd. 2009;73:378-85.
30. Palza H, Quijada R, Delgado K. Antimicrobial polymer composites with copper micro- and nanoparticles: effect of particle size and polymer matrix. J Bioact Compat Polym. 2015;30:366-80.

31. Thomas SF, Rooks P, Rudin F, Atkinson S, Goddard P, Bransgrove R, et al. The bactericidal effect of dendritic copper microparticles, contained in an alginate matrix, on Escherichia coli. PLoS One. 2014;9.

32. Cioffi N, Torsi L, Ditaranto N, Tantillo G, Ghibelli L, Sabbatini L, et al. Copper Nanoparticle / Polymer Composites with Antifungal and Bacteriostatic Properties. 2005;5255-5262.

33. Delgado K, Quijada R, Palma R, Palza H. Polypropylene with embedded copper metal or copper oxide nanoparticles as a novel plastic antimicrobial agent. 2011;50-54.

34. Álvarez F, Palomar M, Insausti J, Olaechea P, Cerdá E, De MS, et al. Infecciones nosocomiales por Staphylococcus aureus en pacientes críticos en unidades de cuidados intensivos. Med Clin (Barc) Elsevier. 2006:126:641-6.

35. Dantes $R$, Mu Y, Belflower R, Aragon D, Dumyati G, Harrison LH, et al. National Burden of Invasive Methicillin-Resistant 2013;30333.

36. Nathwani D, Raman G, Sulham K, Gavaghan M, Menon V. Clinical and economic consequences of hospital-acquired resistant and multidrugresistant Pseudomonas aeruginosa infections : a systematic review and meta-analysis. 2014;

37. Schmidt MG, Attaway HH, Sharpe PA, John J, Sepkowitz KA, Morgan A, et al Sustained reduction of microbial burden on common hospital surfaces through introduction of copper. J Clin Microbiol. 2012;50:2217-23.

\section{Ready to submit your research? Choose BMC and benefit from:}

- fast, convenient online submission

- thorough peer review by experienced researchers in your field

- rapid publication on acceptance

- support for research data, including large and complex data types

- gold Open Access which fosters wider collaboration and increased citations

- maximum visibility for your research: over $100 \mathrm{M}$ website views per year

At $\mathrm{BMC}$, research is always in progress.

Learn more biomedcentral.com/submissions 